\title{
Characterization of insulin-loaded alginate nanoparticles produced by ionotropic pre-gelation through DSC and FTIR studies
}

\author{
Bruno Sarmento $^{\mathrm{a}, *}$, Domingos Ferreira ${ }^{\mathrm{a}}$, Francisco Veiga ${ }^{\mathrm{b}}$, António Ribeiro ${ }^{\mathrm{c}}$ \\ a Department of Pharmaceutical Technology, Faculty of Pharmacy University of Porto, Porto, Portugal \\ ${ }^{\mathrm{b}}$ Department of Pharmaceutical Technology, Faculty of Pharmacy University of Coimbra, Coimbra, Portugal \\ ${ }^{\mathrm{c}}$ Department of Pharmaceutical Technology, Instituto Superior de Ciências da Saúde-Norte, Gandra, Portugal
}

Received 17 January 2006; received in revised form 10 February 2006; accepted 10 February 2006

Available online 31 March 2006

\begin{abstract}
Insulin-loaded nanoparticles were prepared by ionotropic pre-gelation of alginate with calcium chloride followed by complexation between alginate and chitosan. The influence of the $\mathrm{pH}$ and stoichiometry relationship between polyelectrolytes providing individual particles with a nano-scale size was assessed by photon correlation spectroscopy (PCS) and scanning electron microscopy (SEM). Insulinpolyelectrolyte interactions at varying $\mathrm{pH}$ and polyelectrolytes stoichiometry were assessed by differential scanning calorimetry (DSC) and Fourier-transform infrared (FTIR) studies. Individual and smaller sizing nanoparticles, around $800 \mathrm{~nm}$, were obtained at pH 4.7 with an alginate:chitosan mass ratio of 6:1. Thermograms of insulin-loaded nanoparticles originated shifts on same unloaded nanoparticle peaks and suggested polyelectrolytes-protein interactions at $\mathrm{pH}$ around 4.5-5.0. FTIR spectra of insulin-loaded nanoparticles showed amide absorption bands characteristic of protein spectra and revealed the formation of new chemical entities.
\end{abstract}

(C) 2006 Elsevier Ltd. All rights reserved.

Keywords: Alginate; Chitosan; DSC; FTIR; Insulin; Nanoparticles

\section{Introduction}

Nanoparticles made of polyelectrolytes complexation have shown potential for use as drug delivery systems. Polyelectrolyte complexes (PEC) are formed when oppositely charged polyelectrolytes are mixed and interact via electrostatic interactions. Chitosan and alginate are polycation and polyanion polyelectrolytes, respectively, that can be used to form a polyelectrolyte complex and to deliver proteins (Sarmento et al., in press), peptidic drugs (Coppi, Iannuccelli, Leo, Bernabei, \& Cameroni, 2001) and DNA (Douglas \& Tabrizian, 2005).

The interaction between alginate in dilute solution with $\mathrm{Ca}^{2+}$ occurs at a certain ion concentration (Rajaonarivony, Vauthier, Couarraze, Puisieux, \& Couvreur, 1993). A pregel state results with stirring, avoiding the gel point and

\footnotetext{
* Corresponding author. Tel.: +351 222078900; fax: +351 222003977.

E-mail address: bruno.sarmento@ff.up.pt (B. Sarmento).
}

forming a continuous system. Subsequent addition of an aqueous polycationic solution (chitosan) results in a polyelectrolyte complex, stabilizing the alginate pre-gel nucleus into individual sponge-like nanoparticles (Sarmento, Ribeiro, Veiga, Neufeld, \& Ferreira, 2005).

Many studies have been published on individual chitosan-alginate systems (De \& Robinson, 2003; Lee, Park, $\& \mathrm{Ha}, 1997)$. Although parameters such as the molecular weight, temperature, and $\mathrm{pH}$ have been studied to some extent, most of these studies are performed under specific and limited $\mathrm{pH}$ and stoichiometric conditions. Few attempts have been made to compare the properties of complexes formed between chitosan and alginate with and without protein and to rationalize the results in terms of the molecular properties of the protein-containing complexes.

The use of polyelectrolyte complexes as protein delivery systems may result in an overall higher level of electrostatic interactions due to the presence of protein. The control of 
particles size remains a main challenge but the retention of biological activity of encapsulant has been reported (Silva, Ribeiro, Figueiredo, Goncalves, \& Veiga, 2006).

Differential scanning calorimetry (DSC) can be used to characterize the thermal behaviour of polyelectrolytes and biomolecules which is correlated to their structure, hydrophilic properties and association state. It is based on the heat capacity of the sample as a function of the temperature. It is possible in one experiment to obtain the complete temperature profile of the Gibbs energy change associated with the loss of water in polymers, with the denaturation process in proteins and with depolymerization at high temperatures. Shifts of exothermic and endothermic peaks are usually associated with interactions between drugs and polymer (Borges, Borchard, Verhoef, Sousa, \& Junginger, 2005; Ribeiro, Silva, Ferreira, \& Veiga, 2005; Wong, Chan, Kho, \& Heng, 2002).

Fourier transform infrared (FTIR) analysis has also been proposed to examine interactions between polyelectrolyte complexes (Dupuy, Arien, \& Minnot, 1994; Ribeiro et al., 2005).

With these series of experiments it was intended to monitorize the complexation of contrary charged polyelectrolytes as insulin nanoparticulate carriers. Systems resulting from complexation of polyelectrolytes at varying $\mathrm{pH}$ and stoichiometric relationship between polyelectrolytes were lyophilized, and analyzed by DSC and FTIR to verify interactions between polyelectrolytes and between polymers and insulin.

\section{Materials and methods}

Low viscosity sodium alginate with a low guluronic content $\left(F_{\mathrm{G}}=0.39\right)$, low molecular weight (MW) chitosan $(\approx 50 \mathrm{kDa})$ and calcium chloride were purchased from Sigma (Oakville, Canada). Alginate solution was prepared in deionized water (Milli- $\mathrm{Q}^{\circledR}$ ) overnight under magnetic stirring and chitosan sample was dissolved in $1 \%$ acetic acid solution in deionized water followed by filtration by using a Millipore \#2 paper filter and stored at $4{ }^{\circ} \mathrm{C}$. Human zinc-insulin crystal was a gift from Lilly Farma, Portugal.

\subsection{Nanoparticle preparation}

Alginate/chitosan nanoparticles were prepared in a twostep procedure based on the ionotropic pre-gelation of polyanion with calcium chloride followed by polycationic crosslinking through a protocol earlier described (Rajaonarivony et al., 1993), modified according to ideal pre-gelation stoichiometric ratio and time of drug association (Sarmento et al., 2005). Thus, $7.5 \mathrm{ml}$ of $18 \mathrm{mM}$ calcium chloride solution was dropped for $60 \mathrm{~min}$ under $800 \mathrm{rpm}$ into a beaker containing $117.5 \mathrm{ml}$ of a $0.063 \%$ $(w / w)$ alginate solution. An amount of insulin equivalent to 200 UI was mixed with the alginate solution before calcium chloride addition to provide an alginate pre-gel. Then, $25 \mathrm{ml}$ of different concentration $(0.05-0.09 \%$, w/w) chitosan solution was added dropwise into the pre-gel over $120 \mathrm{~min}$. The $\mathrm{pH}$ of alginate and chitosan solutions was initially set to 4.9 and 4.6 to provide a colloidal dispersion with final $\mathrm{pH}$ of 4.7 , but further modified to provide a final $\mathrm{pH}$ of 4.2 and 5.2. Nanoparticles were held with an additional stirring for $30 \mathrm{~min}$ to improve curing, and separated by centrifugation $(20000 \mathrm{~g} / 45 \mathrm{~min})$ at $4{ }^{\circ} \mathrm{C}$.

\subsection{Nanoparticle characterization}

\subsubsection{Morphology}

Nanoparticles granulometry was assessed by PCS using a Malvern Zetasizer and Scattering Particle Size Analyzer (Malvern Instruments, UK). A sample of $5 \mathrm{ml}$ was gently shaked, placed into analyzer chamber and measured. Collective 10 readings were performed three times on a sample of particles at $25^{\circ} \mathrm{C}$ with a detection angle of $90^{\circ}$.

Nanoparticulate systems morphology such as shape and occurrence of aggregation phenomena, was studied by scanning electron microscopy (SEM). Samples of nanoparticles were mounted on metal stubs, gold coated under vacuum and then examined on a JEOL JSM-840 SEM (10 kV, Japan).

\subsubsection{FTIR analysis}

IR-spectra were obtained using a Bomem IR-spectrometer (Bomem, Canada). Samples were lyophilized, gently mixed with $300 \mathrm{mg}$ of micronized $\mathrm{KBr}$ powder and compressed into discs at a force of $10 \mathrm{kN}$ for 2 min using a manual tablet presser (Perkin Elmer, Norwalk, USA). For each spectrum a 256-scan interferogram was collected with a $4 \mathrm{~cm}^{-1}$ resolution in the mid-IR region at room temperature. Insulin spectra were obtained according to a double subtraction procedure (Dong, Huang, \& Caughey, 1990) and insulin-free systems and water vapor spectra were collected under identical conditions for blank subtraction. All samples were run in triplicate and the data presented are the average of the three measurements.

\subsubsection{DSC analysis}

Thermograms were obtained using a Shimadzu DSC-50 system (Shimadzu, Kyoto, Japan). Samples were lyophilized, $2.0 \mathrm{mg}$ of lyophilized powder crimped in a standard aluminium pan and heated from 20 to $350{ }^{\circ} \mathrm{C}$ at a heating constant rate of $10^{\circ} \mathrm{C} / \mathrm{min}$ under constant purging of nitrogen at $20 \mathrm{ml} / \mathrm{min}$. All samples were run in duplicate.

\section{Results and discussion}

Particle size is determinant in mucosal and epithelial tissue uptake of particles and in the intracellular traffic of the particles (Panyam \& Labhasetwar, 2003). Drug carriers sizing few microns have shown higher potential as oral delivery systems of proteins and peptides (Chen \& Langer, 1998). Granulometric distribution of chitosan-alginate nanoparticles depend on concentration and molecular weight of both polyelectrolytes, and conditions of mixing 
(Sarmento et al., in press). Besides, protein encapsulants have shown an increasing size effect on nanoparticulate carriers made of polyelectrolytes complexation. The effect of chitosan to alginate mass ratio on particle size showed an increase of size from 764 to $2209 \mathrm{~nm}$ with decreasing chitosan to alginate mass ratio from 6:1 to 3.3:1. (Table 1). These relationships provide a processing window for manipulating particles in both nano and microsize range and optimizing the nanosize for intended applications. Also, nanoparticle size appears to present a relatively narrow distribution according to values of SD obtained and as displayed in Fig. 1.

The effect of $\mathrm{pH}$ on nanoparticle size is shown in Table 2. The $\mathrm{pH}$ range was chosen to allow contrary charges of polyelectrolytes in order to provide the formation of nanoparticles. The decrease of $\mathrm{pH}$ from 5.2 to 4.7 slightly decreased the mean particle size of obtained nanoparticles, but the opposite effect was observed by decreasing the $\mathrm{pH}$ from 4.7 to 4.2 since the mean size of particles significantly increased when $\mathrm{pH}$ of aqueous solution reached values around 4 . It is believed that at this $\mathrm{pH}$ range, alginate approaches its $\mathrm{p} K_{\mathrm{a}}$ values, the first of guluronic acid around 3.7 (Haug, 1964), and a significant part of it starts precipitating and aggregating, which may contribute to increase the particle size mean value measured by PCS.

Table 1

Characterization of alginate/chitosan nanoparticles produced at $\mathrm{pH} 4.7$ in terms of mean size $( \pm \mathrm{SD})$ as a function of alginate/chitosan mass ratio $(n=3)$

\begin{tabular}{lc}
\hline Alginate:chitosan mass ratio & Mean size $(\mathrm{nm})$ \\
\hline $6: 1$ & $764 \pm 76$ \\
$4.3: 1$ & $797 \pm 48$ \\
$3.3: 1$ & $2209 \pm 496$ \\
\hline
\end{tabular}

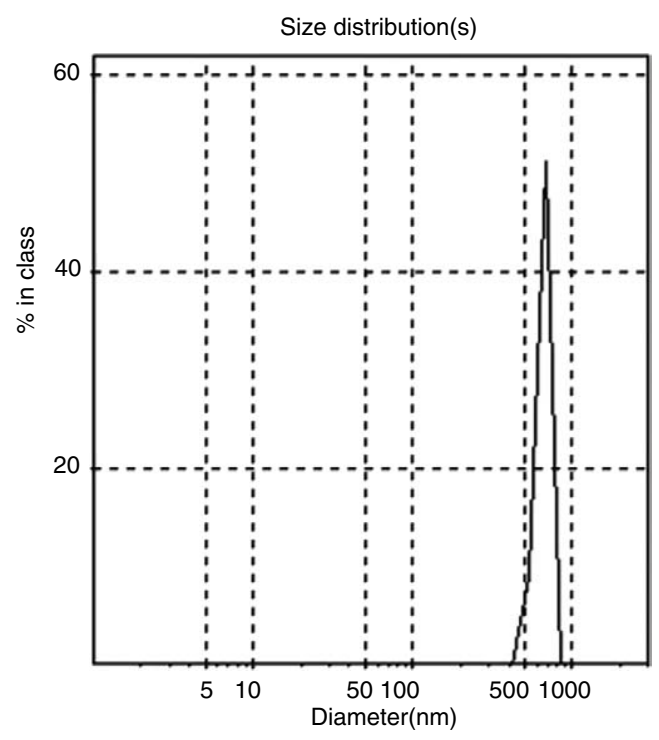

Fig. 1. Particle size analysis of insulin-loaded nanoparticles produced with alginate:chitosan mass ratio of 4.3:1 at $\mathrm{pH} 4.7$.
Fig. 2 shows the SEM images of the chitosan-alginate particles. Nanoparticle surface showed an irregular shape and morphology related to a generic spherical shape.

Table 3 presents the endothermic and exothermic peaks and enthalpies associated with each peak for insulin, alginate, chitosan, physical mixtures, and nanoparticles obtained by complexation of polyelectrolytes at $\mathrm{pH} 4.7$. Also, the thermogram of insulin-loaded alginate/chitosan nanoparticles is summarized.

In Fig. 3 we can see the thermograms of alginate and chitosan which show initial endothermic peaks at 86.6 and $62.0^{\circ} \mathrm{C}$ and higher exothermic peaks at 247.8 and $311.0^{\circ} \mathrm{C}$, respectively. Endothermic peaks are correlated with loss of water associated to hydrophilic groups of polymers while exothermic peaks resulted from degradation of polyelectrolytes due to dehydration and depolymerization reactions most probably to the parcial decarboxilation of the protonated carboxylic groups and oxidation reactions of the polyelectrolytes (Mimmo, Marzadori, Montecchio, \& Gessa, 2005; Soares, Santos, Chierice, \& Cavalheiro, 2004; Zohuriaan \& Shokrolahi, 2004). Thermogram of alginate/chitosan physical mixture show a broader endothermic peak at $76.7^{\circ} \mathrm{C}$, which probably represents the coalescence of both isolated endothermic polymer peaks and exothermic peaks at 250.4 and $309.6^{\circ} \mathrm{C}$ resulted from individual contribution of alginate and chitosan, respectively.

\section{Table 2}

Characterization of alginate/chitosan nanoparticles produced with alginate:chitosan mass ratio of 4.3:1 in terms of mean size $( \pm \mathrm{SD})$ as a function of system's final $(n=3)$

\begin{tabular}{lc}
\hline $\mathrm{pH}$ of nanoparticle production & Mean size $(\mathrm{nm})$ \\
\hline 4.2 & $2858 \pm 376$ \\
4.7 & $797 \pm 48$ \\
5.2 & $1062 \pm 210$ \\
\hline
\end{tabular}

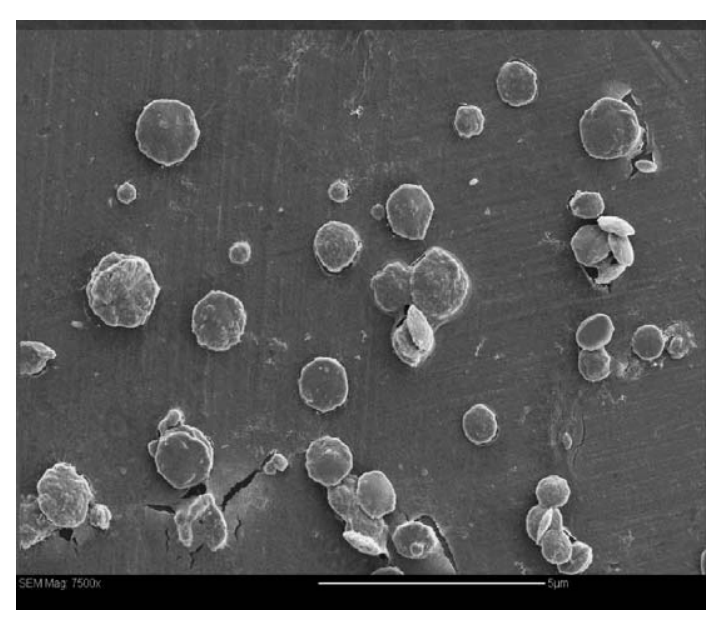

Fig. 2. SEM micrographs of alginate/chitosan nanoparticles produced with alginate:chitosan mass ratio of $4.3: 1$ at $\mathrm{pH} 4.7$. 
Table 3

Peak temperatures and enthalpy changes in the DSC thermograms collected from insulin, polysaccharides, physical mixtures, and nanoparticles

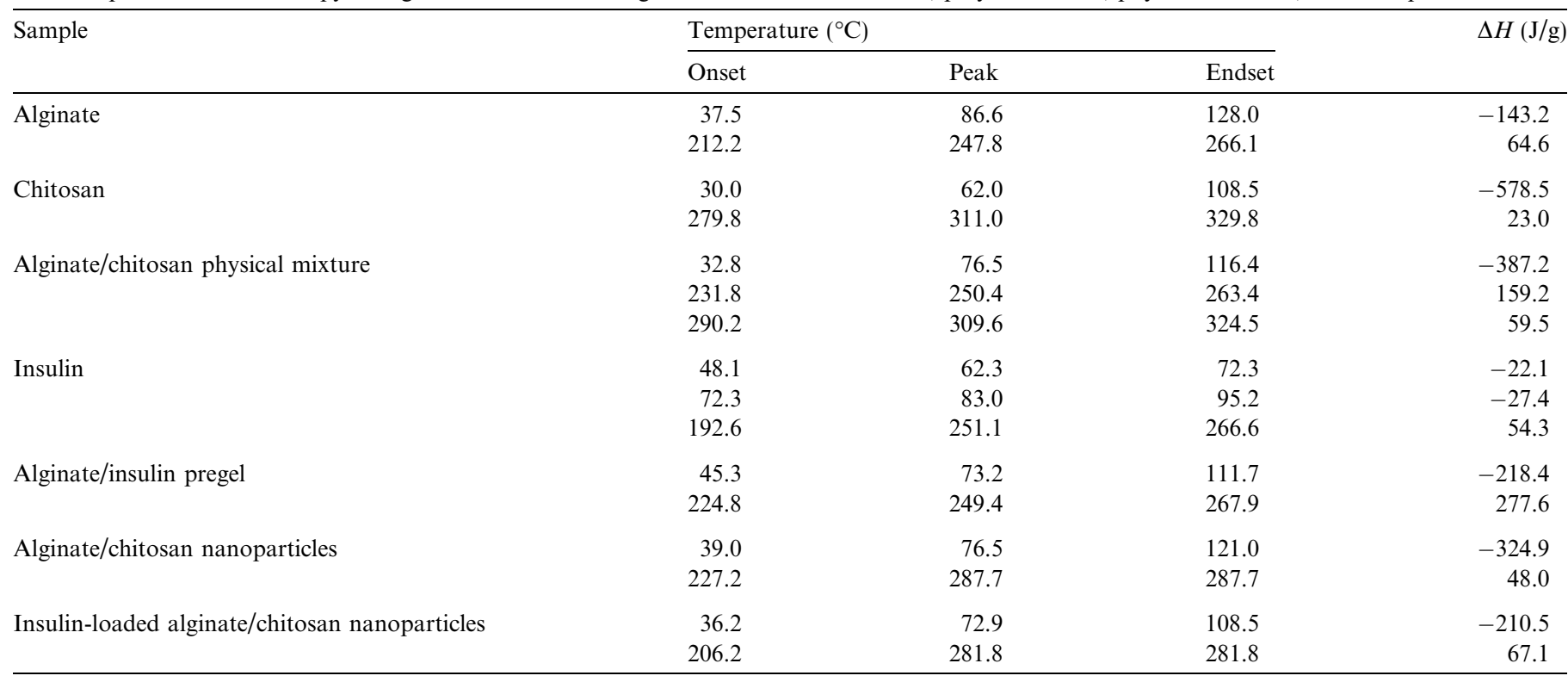

Unloaded and insulin-loaded nanoparticles were obtained by chitosan/alginate complexation at pH 4.7 and mass ratio of 4.3:1.

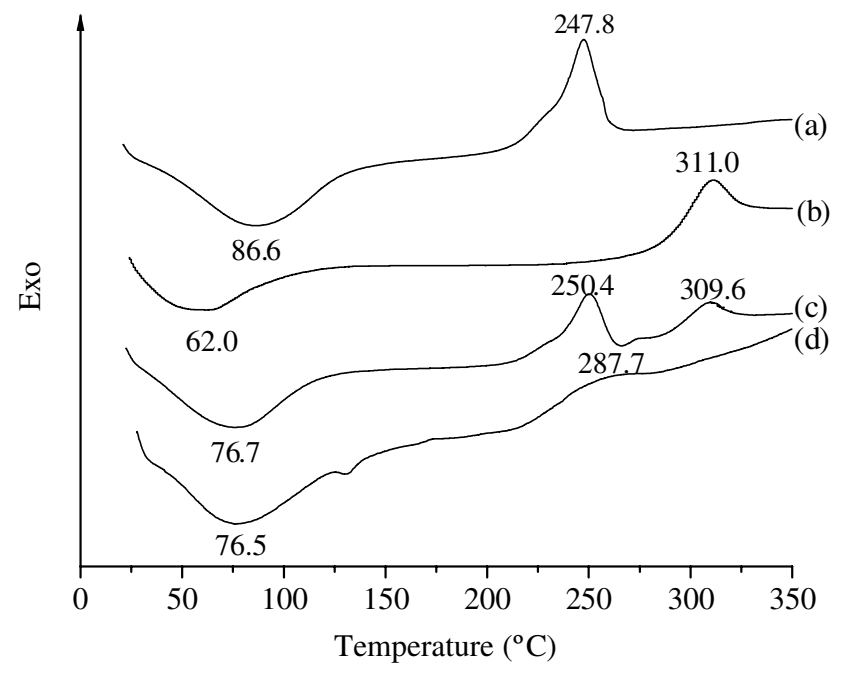

Fig. 3. Thermograms of (a) alginate at $\mathrm{pH} 4.9$, (b) chitosan at $\mathrm{pH} 4.6$, (c) chitosan/alginate physical mixture, and (d) alginate/chitosan nanoparticles produced at $\mathrm{pH} 4.7$.

It could be seen that the peaks of the complexes were shifted from those of physical mixture. Peaks of physical mixture appeared to be combinations of each material but they are different from those of nanoparticles probably because complexation of polyelectrolytes resulted in new chemical bonds. Exothermic peak of alginate/chitosan nanoparticles was registered at $287.7^{\circ} \mathrm{C}$, an intermediate and broader peak value compared with isolate polyelectrolytes, which was interpreted as an interaction between both components.

Thermograms of alginate/chitosan nanoparticles prepared at three different $\mathrm{pH}$ environments, are shown in Fig. 4.

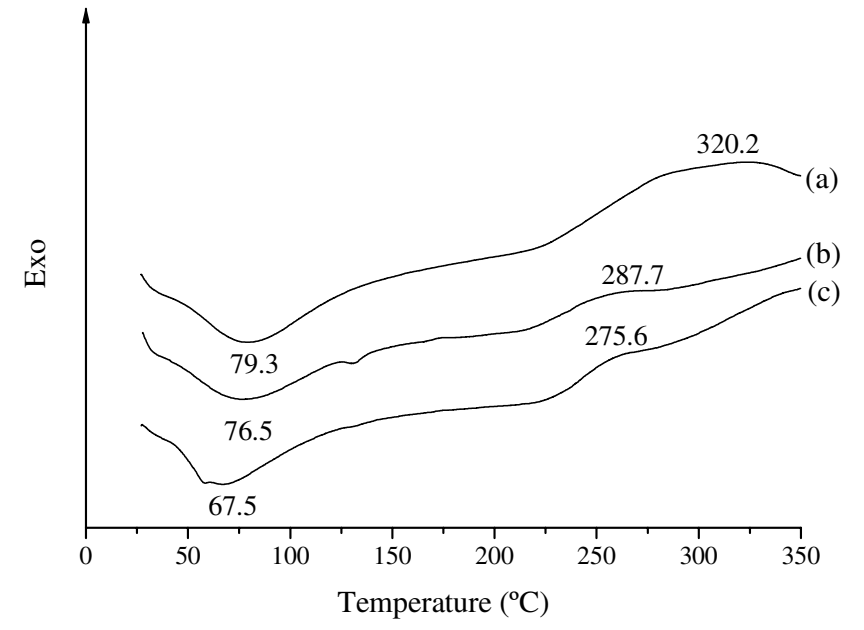

Fig. 4. Thermograms of alginate/chitosan nanoparticles produced at (a) $\mathrm{pH} 4.2$, (b) 4.7, and (c) 5.2.

Both endothermic and exothermic peaks shifted to higher temperature values when $\mathrm{pH}$ of nanoparticles preparation was decreased from 5.2 to 4.2 . It can be realized that at lower $\mathrm{pH}$ resulted higher stability of complexes, thus more energy was required to remove residual water adsorbed to nanoparticles (also endothermic peak shifts to higher value), and less energy was released by braking ionic interactions and during nanoparticle thermal decomposition (also exothermic peak shift to higher value).

The $\mathrm{p} K$ values of mannuronic acid $(\mathrm{M})$ and guluronic acid $(\mathrm{G})$ of alginate chain are $\mathrm{p} K_{\mathrm{M}} 3.38$ and $\mathrm{p} K_{\mathrm{G}} 3.65$, respectively (Haug, 1964) and the $\mathrm{p} K$ value of chitosan is $\sim 6.3$ (Berger et al., 2004). It was also found that amine groups of chitosan polymer had more affinity to $M$ residues than $G$ residues of alginate (Dupuy et al., 1994). The algi- 
nate used for these experiences is a high-M $\left(F_{\mathrm{M}}=0.61\right)$, which means that overall $\mathrm{p} K$ of alginate is close to $\mathrm{p} K_{\mathrm{M}}$ and maximum ionic interaction between alginate and chitosan is attained at lower $\mathrm{pH}$ as compared to a high$\mathrm{G}$ alginate. Also, alginate gel is shrinked at lower $\mathrm{pH}$ values and a reduction of the pore size of alginate matrix can be achieved (Gombotz \& Wee, 1998), specially in the case of low $\mathrm{G}$ content alginate used in the present work that acquire highest shrinkage properties. Therefore, at $\mathrm{pH} 4.2$ it is possible that nanoparticles presented a stronger

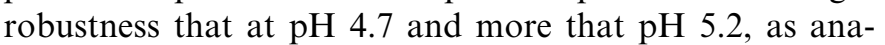
lyzed. The interaction between alginate and chitosan is known to be $\mathrm{pH}$-dependent and stronger complexes were also obtained at $\mathrm{pH}$ around 4.5-5.0 (Lee et al., 1997; Liu et al., 2004).

The effect of alginate:chitosan mass ratio on the nanoparticles was also evaluated through calorimetry and depicted in Fig. 5. By increasing the final amount of chitosan on nanoparticles weight, it was observed an increase of the value of exothermic peak. Nanoparticles produced with alginate:chitosan mass ratio of $6: 1,4.3: 1$, and $3.3: 1$ presented an exothermic peak at $270.1,287.7$, and $337.7^{\circ} \mathrm{C}$, respectively. However, the increasing effect of final amount of chitosan on the value of initial endothermic peak was less evident than the one observed for the influence of $\mathrm{pH}$. The results obtained could lead to the assumption that decreasing alginate:chitosan mass ratio by increasing initial chitosan mass on nanoparticles originated different degree of interaction between polymers, suggesting the obtention of more stable polyelectrolyte complexes with a higher amount of chitosan.

The thermogram of zinc-insulin showed two endothermic peaks at 62.3 and $83.0^{\circ} \mathrm{C}$ and a tiny and broad exothermic peak at $251.1^{\circ} \mathrm{C}$. This thermogram pattern of insulin is in agreement with other reported in literature (Jorgensen, Weert, Vermehren, Bjerregaard, \& Frokjaer, 2004; Pikal \& Rigsbee, 1997). This biphasic denaturation

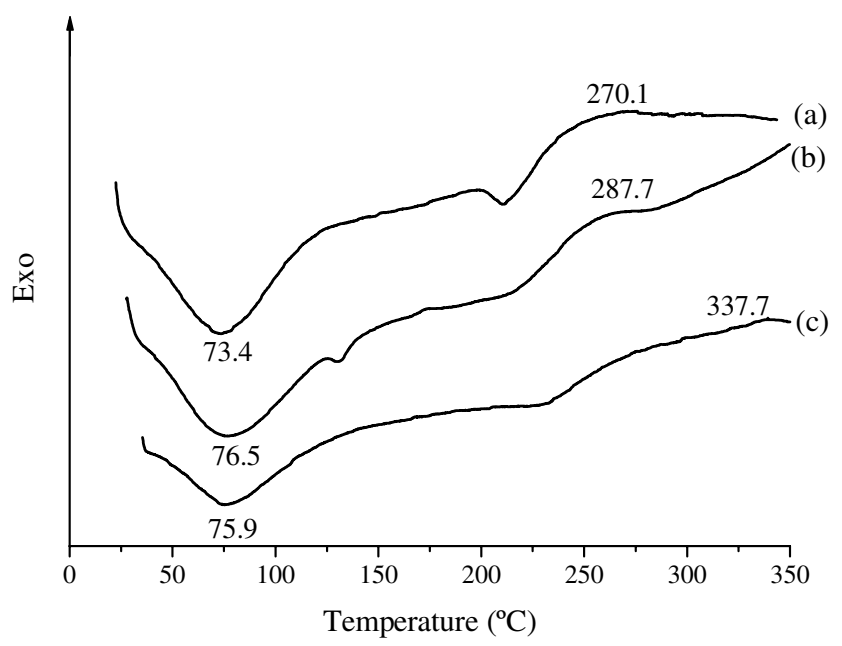

Fig. 5. Thermograms of alginate/chitosan nanoparticles produced with alginate:chitosan mass ratio of (a) 6:1, (b) 4.3:1, and (c) 3.3:1. of the zinc-insulin complex is a result of the coupling between insulin denaturation and zinc binding equilibria. Comparing to zinc-free insulin, the endotherm of insulin hexamers involves both dissociation and unfolding, whereas the endotherm of zinc-free insulin does not show dissociation behaviour (Huus, Havelund, Olsen, van de Weert, \& Frokjaer, 2005). Figs. 6 and 7 represent the thermal differences of alginate pre-gel and alginate/chitosan nanoparticles, respectively, before and after insulin entrapment.

The two endothermic peaks associated to insulin which are attributed to denaturation process and water loss, became indistinct and transformed themselves into a single peak after insulin entrapment into the alginate pre-gel and alginate/chitosan nanoparticles. Insulin-loaded systems reached this endothermic condition at lower temperature values comparing to unloaded nanoparticles, thus an interaction between the protein and the polyelectrolytes

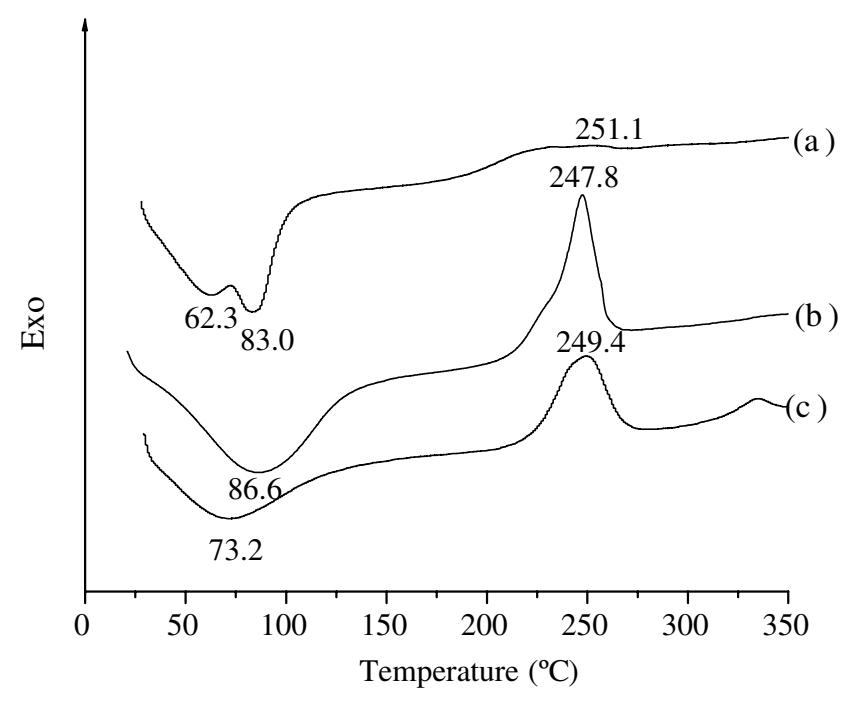

Fig. 6. Thermograms of (a) insulin, (b) alginate at $\mathrm{pH} 4.9$, and (c) insulinloaded alginate pre-gel.

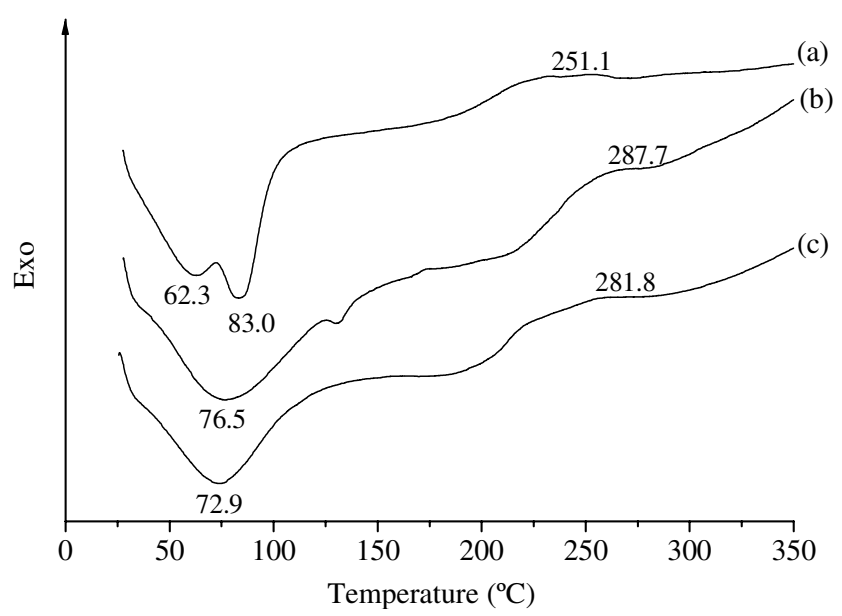

Fig. 7. Thermograms of (a) insulin (b) alginate/chitosan nanoparticles, and (c) insulin-loaded alginate/chitosan nanoparticles produced at $\mathrm{pH} 4.7$. 
could have occurred. Also, comparing exothermic peak of insulin-loaded alginate/chitosan nanoparticles to the one obtained with unloaded nanoparticles, the former started at lower temperature, which is a possible evidence of the presence of insulin once its decomposition started at lower temperature $251.1^{\circ} \mathrm{C}$ when comparing to unloaded nanoparticles (Table 4).

In order to examine the relationship between components of nanoparticulate systems, preliminary concerns were taken over polyelectrolytes interactions and insulin entrapment. It is well established that the carboxyl group $\left(-\mathrm{COO}^{-}\right)$of the anionic polymer may interact with the amino group $\left(-\mathrm{NH}_{3}{ }^{+}\right)$of chitosan and form an ionic complex between the two compounds (Ribeiro et al., 2005). As a result, there are changes in the FTIR spectra in the absorption bands of the amino groups, carboxyl groups, and amide bonds.

Fig. 8 represents FTIR spectra of pure alginate, chitosan, and alginate/chitosan nanoparticles.

We can see alginate carboxyl peaks near $1613 \mathrm{~cm}^{-1}$ (symmetric $\mathrm{COO}^{-}$stretching vibration) and $1415 \mathrm{~cm}^{-1}$ (asymmetric $\mathrm{COO}$ stretching vibration) broaden and slightly shifted from 1613 to 1610 and 1415 to 1414 after complexation with chitosan. The FTIR spectrum of chitosan also shows a peak of amide bond at $1641 \mathrm{~cm}^{-1}$ and a strong protonated amino peak at $1569 \mathrm{~cm}^{-1}$ because it is obtained from partial $N$-deacetylation of chitin. However, both peaks were similarly shifted by few $\mathrm{cm}^{-1}$ after complexation with alginate, the amide peak into singlet band at $1610 \mathrm{~cm}^{-1}$ and the amino peak to $1534 \mathrm{~cm}^{-1}$. Observed changes in the absorption bands of the amino groups, carboxyl groups, and amide bonds can be attributed to an ionic interaction between the carbonyl group of alginate and the amino group of chitosan (Ribeiro et al., 2005). In addition,

Table 4

Peak temperatures and enthalpy changes in the DSC thermograms collected from nanoparticulate complexes obtained with a varying stoichiometry of alginate/chitosan at varying $\mathrm{pH}$

\begin{tabular}{lrrrc}
\hline Sample & \multicolumn{3}{c}{ Temperature $\left({ }^{\circ} \mathrm{C}\right)$} & \multirow{2}{*}{$\Delta H(\mathrm{~J} / \mathrm{g})$} \\
\cline { 2 - 4 } & Onset & \multicolumn{1}{c}{ Peak } & Endset & \\
\hline Alginate:chitosan mass ratio 4.3:1 & & & & \\
pH 4.2 & 41.9 & 79.3 & 125.5 & -374.2 \\
& 233.8 & 320.2 & 320.2 & 128.2 \\
pH 4.7 & 39.0 & 76.5 & 121.0 & -324.9 \\
& 227.2 & 287.7 & 287.7 & 48.0 \\
pH 5.2 & 43.95 & 67.5 & 111.2 & -306.5 \\
& 229.7 & 275.6 & 275.6 & 32.11 \\
Alginatelchitosan nanoparticles pH & 4.7 & & & \\
Alginate:chitosan mass ratio 6.0:1 & 44.6 & 73.4 & 112.9 & -448.1 \\
& 224.0 & 286.8 & 292.8 & 89.55 \\
Alginate:chitosan mass ratio 4.3:1 & 39.0 & 76.5 & 121.0 & -324.9 \\
& 227.2 & 287.7 & 287.7 & 48.0 \\
Alginate:chitosan mass ratio 3.3:1 & 39.2 & 75.9 & 101.2 & -200.9 \\
& 305.5 & 337.7 & 346.8 & 8.73 \\
\hline
\end{tabular}

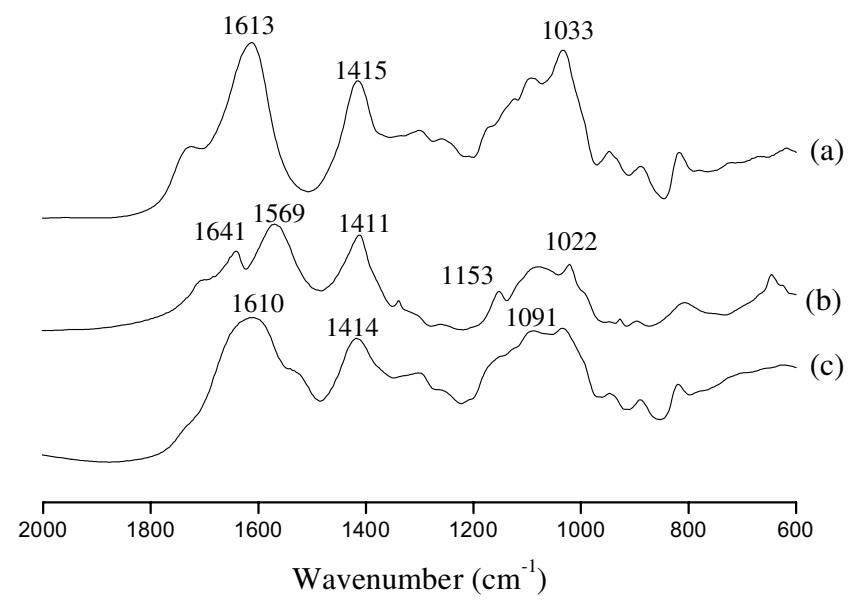

Fig. 8. FTIR spectra of solid (a) alginate, (b) chitosan, and (c) alginate/ chitosan nanoparticles produced with alginate:chitosan mass ratio of 4.3:1 at $\mathrm{pH} 4.7$.

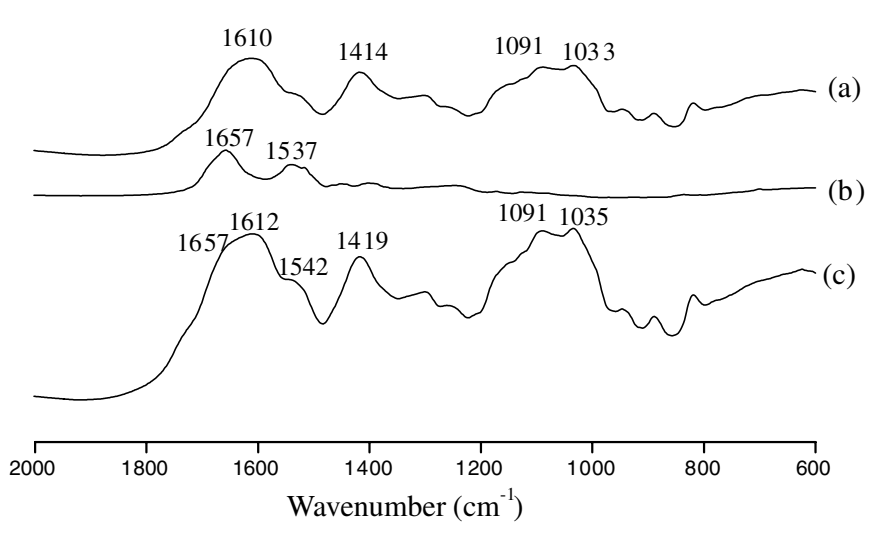

Fig. 9. FTIR spectra of solid (a) alginate/chitosan nanoparticles, (b) insulin, and (c) insulin-loaded alginate/chitosan nanoparticles produced with alginate:chitosan mass ratio of 4.3:1 at $\mathrm{pH} 4.7$.

the peak absorbance of amino groups of chitosan at $1153 \mathrm{~cm}^{-1}$ was also present after complexation and absent in alginate. Similar observations were noted previously (Mitrevej, Sinchaipanid, Rungvejhavuttivittaya, \& Kositchaiyong, 2001). These results suggest an effective interaction between polymers and seem to be in agreement with the stoichiometric ratios between them indicating a prevalence of alginate in the final blend.

The introduction of insulin into nanoparticles was also investigated by FTIR analysis of insulin-loaded nanoparticles. The obtained spectra are represented in Fig. 9 and revealed two shoulders on the nanoparticles absorption bands in the Amide I $\left(\sim 1650 \mathrm{~cm}^{-1}\right)$ and Amide II $\left(\sim 1540 \mathrm{~cm}^{-1}\right)$, which are characteristic of protein spectra. The insulin monomer contains many ionizable groups, due to six amino acid residues capable of attaining a positive charge and 10 amino acid residues capable of attaching a negative charge (Brange, 1987). These properties are, therefore, possibly responsible for the entrapment of insulin into alginate/chitosan nanoparticles. 


\section{Conclusion}

DSC and FTIR were successfully used to characterize the nanoparticulate systems made up by polyelectrolyte complexes. Shifts on endothermic and exothermic peaks and shifts on maximum infrared peaks observed between individual polyelectrolytes and final nanoparticle carriers were understand as ionic interactions which led to the formation of new chemical entities with different thermal and absorption properties. Additionally, insulin entrapment also originated small shifts on same nanoparticle peaks, a clear influence of the protein on final formulation as an entrapped drug.

\section{Acknowledgements}

This work was supported by Fundação para a Ciência e Tecnologia, Portugal and the Natural Sciences and Engineering Research Council of Canada. The authors thank Lilly Portugal for insulin supply and Marco van de Weert and Lene Jorgensen from Danish University of Pharmaceutical Sciences for FTIR equipment facilities.

\section{References}

Berger, J., Reist, M., Mayera, J. M., Felt, O., Peppas, N. A., \& Gurny, R. (2004). Structure and interactions in covalently and ionically crosslinked chitosan hydrogels for biomedical applications. European Journal of Pharmaceutics and Biopharmaceutics, 57, 19-34.

Borges, O., Borchard, G., Verhoef, J. C., Sousa, A., \& Junginger, H. E. (2005). Preparation of coated nanoparticles for a new mucosal vaccine delivery system. International Journal of Pharmaceutics, 299(1-2), $155-166$.

Brange, J. (1987). Galenics of insulin: The physico-chemical and pharmaceutical aspects of insulin and insulin preparations. Berlin: Springer.

Chen, H., \& Langer, R. (1998). Oral particulate delivery: Status and future trends. Advanced Drug Delivery Reviews, 34(2-3), 339-350.

Coppi, G., Iannuccelli, V., Leo, E., Bernabei, M. T., \& Cameroni, R. (2001). Chitosan-alginate microparticles as a protein carrier. Drug Development and Industrial Pharmacy, 27(5), 393-400.

De, S., \& Robinson, D. (2003). Polymer relationships during preparation of chitosan-alginate and poly-L-lysine-alginate nanospheres. Journal of Controlled Release, 89(1), 101-112.

Dong, A., Huang, P., \& Caughey, W. S. (1990). Protein secondary structures in water from second-derivative amide I infrared spectra. Biochemistry, 29, 3303-3308.

Douglas, K. L., \& Tabrizian, M. (2005). Effect of experimental parameters on the formation of alginate-chitosan nanoparticles and evaluation of their potential application as DNA carrier. Journal of Biomaterials Science, Polymer Edition, 16(1), 43-56.

Dupuy, B., Arien, A., \& Minnot, A. P. (1994). FT-IR of membranes made with alginate/polylysine complexes. Variations with the mannuronic or guluronic content of the polysaccharides. Artificial Cells, Blood Substitutes, and Immobilization Biotechnology, 22(1), 71-82.
Gombotz, W. R., \& Wee, S. F. (1998). Protein release from alginate matrices. Advanced Drug Delivery Reviews, 31, 267-285.

Haug, A. (1964). Composition and properties of alginates. Thesis Trondheim Norwegian Institute of Technology.

Huus, K., Havelund, S., Olsen, H. B., van de Weert, M., \& Frokjaer, S. (2005). Thermal dissociation and unfolding of insulin. Biochemistry, 44(33), 11171-11177.

Jorgensen, L., Weert, M. v. d., Vermehren, C., Bjerregaard, S., \& Frokjaer, S. (2004). Probing structural changes of proteins incorporated into water-in-oil emulsions. Journal of Pharmaceutical Sciences, 93, 1847-1859.

Lee, K. Y., Park, W. H., \& Ha, W. S. (1997). Polyelectrolyte complexes of sodium alginate with chitosan or its derivatives for microcapsules. Journal Applied Polymer Science, 63, 425-432.

Liu, X., Xue, W., Liu, Q., Yu, W., Fu, Y., Xiong, X., et al. (2004). Swelling behaviour of alginate-chitosan microcapsules prepared by external gelation or internal gelation technology. Carbohydrate Polymers, 56(4), 459-464.

Mimmo, T., Marzadori, C., Montecchio, D., \& Gessa, C. (2005). Characterisation of $\mathrm{Ca}$ - and $\mathrm{Al}$-pectate gels by thermal analysis and FT-IR spectroscopy. Carbohydrate Research, 340(16), 2510-2519.

Mitrevej, A., Sinchaipanid, N., Rungvejhavuttivittaya, Y., \& Kositchaiyong, V. (2001). Multiunit controlled-release diclofenac sodium capsules using complex of chitosan with sodium alginate or pectin. Pharmaceutical Development and Technology, 6(3), 385-392.

Panyam, J., \& Labhasetwar, V. (2003). Biodegradable nanoparticles for drug and gene delivery to cells and tissue. Advanced Drug Delivery Reviews, 55, 329-347.

Pikal, M. J., \& Rigsbee, D. R. (1997). The stability of insulin in crystalline and amorphous solids: Observation of greater stability for the amorphous form. Pharmaceutical Research, 14, 1379-1387.

Rajaonarivony, M., Vauthier, C., Couarraze, G., Puisieux, F., \& Couvreur, P. (1993). Development of a new drug carrier made from alginate. Journal of Pharmaceutical Sciences, 82(9), 912-917.

Ribeiro, A. J., Silva, C., Ferreira, D., \& Veiga, F. (2005). Chitosanreinforced alginate microspheres obtained through the emulsification/ internal gelation technique. European Journal of Pharmaceutical Sciences, 25(1), 31-40.

Sarmento, B., Martins, S., Ribeiro, A., Veiga, F., Neufeld, R., \& Ferreira, D. (in press). Development and comparison of different nanoparticulate polyelectrolyte complexes as insulin carriers. International Journal of Peptide Research and Therapeutics.

Sarmento, B., Ribeiro, A., Veiga, F., Neufeld, R., \& Ferreira, D. (2005). Insulin-loaded alginate/chitosan nanoparticles produced by ionotropic pre-gelation. Revista Portuguesa Farmácia, LII(2), 139-140.

Silva, C. M., Ribeiro, A. J., Figueiredo, I. V., Goncalves, A. R., \& Veiga, F. (2006). Alginate microspheres prepared by internal gelation: Development and effect on insulin stability. International Journal of Pharmaceutics, 311, 1-10.

Soares, J. P., Santos, J. E., Chierice, G. O., \& Cavalheiro, E. T. G. (2004). Thermal behavior of alginic acid and its sodium salt. Eclética Química, 29(2), 57-63.

Wong, T. W., Chan, L. W., Kho, S. B., \& Heng, P. W. S. (2002). Design of controlled-release solid dosage forms of alginate and chitosan using microwave. Journal of Controlled Release, 84(3), 99-114.

Zohuriaan, M. J., \& Shokrolahi, F. (2004). Thermal studies on natural and modified gums. Polymer Testing, 23(5), 575-579. 